\title{
Smith-Lemli-Opitz syndrome II: a disorder of the fetal adrenals?
}

\author{
P A McKeever, I D Young
}

\begin{abstract}
Two cases of Smith-Lemli-Opitz syndrome type II are presented. During the late stages of both pregnancies maternal oestriol levels were unrecordable and there was evidence of suppression of maternal adrenal function. We speculate on the existence of a primary defect in the fetal adrenals.
\end{abstract}

Smith-Lemli-Opitz syndrome type II (SLO II) is a rare and recently delineated lethal malformation syndrome, which is believed to show autosomal recessive inheritance. ${ }^{12}$ Two affected infants are described, each of whom first gave cause for concern because of an abnormal maternal urinary steroid profile during late pregnancy.

\section{Case reports}

CASE 1

A phenotypically female infant weighed $1890 \mathrm{~g}$ ( $<3$ rd centile) after delivery at 38 weeks' gestation and died at 4 hours of age. Obvious external anomalies included an abnormal facies with anteverted nares and micrognathia, a small tongue, low set ears, short neck, short limbs, and small thumbs. The feet showed bilateral talipes calcaneovalgus with $2 / 3$ syndactyly and right sided postaxial polysyndactyly. At necropsy, seminal vesicles and testes were present, the kidneys were noted to be small, and both lungs were found to be unilobular. Blood lymphocytes and fibroblast cultures showed a normal male karyotype. A fuller description of the clinical findings in this baby has been presented elsewhere. ${ }^{3}$

Department of Pathology, Clinical Sciences Building, Leicester Royal Infirmary, Leicester LE2 7LX.

P A McKeever

Department of Child Health, Leicester Royal Infirmary, Leicester LE2 7LX.

I D Young

Correspondence to Dr McKeever.

Received for publication 15 January 1990

Accepted for publication 22 February 1990.
During the last four weeks of pregnancy maternal urinary oestriol levels were consistently low or unrecordable. In contrast, serum human placental lactogen levels were normal. Three days before delivery maternal urinary cortisol precursors $(0 \cdot 7$ $\mu \mathrm{mol} / 24 \mathrm{~h})$, cortisol metabolites $(3.9 \mu \mathrm{mol} / 24 \mathrm{~h})$, and androgen glucuronides $(0.9 \mu \mathrm{mol} / 24 \mathrm{~h})$ were all extremely low. Two weeks after delivery all of these values had reverted to normal.

\section{CASE 2}

A phenotypically female baby of healthy, unrelated parents was stillborn at 33 weeks' gestation with birth weight $1410 \mathrm{~g}$ (10th centile), length $35.5 \mathrm{~cm}$ (<3rd centile), and head circumference $23 \mathrm{~cm}$ ( $<3$ rd centile). Obvious external abnormalities included hypotelorism, bilateral epicanthus, poorly formed nares, low set ears, high arched palate, short limbs, postaxial polydactyly involving the left hand and both feet, and partial bilateral syndactyly of the second and third toes. Necropsy showed a small ostium primum atrial septal defect, hypoplastic lungs (weight $11.2 \mathrm{~g}$, expected weight $34 \pm 11 \mathrm{~g}$ ), very small kidneys (weight $1 \cdot 2 \mathrm{~g}$, expected weight $14.9 \pm 4 \cdot 2 \mathrm{~g}$ ), and large adrenal glands (weight $7 \cdot 5 \mathrm{~g}$, expected weight $4 \cdot 3 \pm 2 \cdot 3 \mathrm{~g}$ ). The brain was small (weight $107 \mathrm{~g}$, expected weight $219 \pm 52 \mathrm{~g}$ ) and showed features within the spectrum of holoprosencephaly, that is, partial fusion of the cerebral hemispheres anteriorly with absence of the first cranial nerves and ventricular septum.

Histological examination of the small kidneys and large adrenals showed normal architecture. However, use of the oil Red $\mathrm{O}$ stain showed complete absence of lipid in the adrenal cortex and this was confirmed by electron microscopy. Sections of the pancreas showed many large islets. Immunocytochemical staining showed normal amounts of insulin and glucagon in the islets but much reduced quantities of somatostatin as compared with normal, age matched controls. Histology of the ovaries, which appeared normal externally, showed a very abnormal architecture with aggregates of epithelial type cells-lying throughout the stroma (figure).

Chromosome studies undertaken on cord blood from this baby showed the presence of a subtle interstitial deletion on the short arm of one $\mathrm{X}$ 


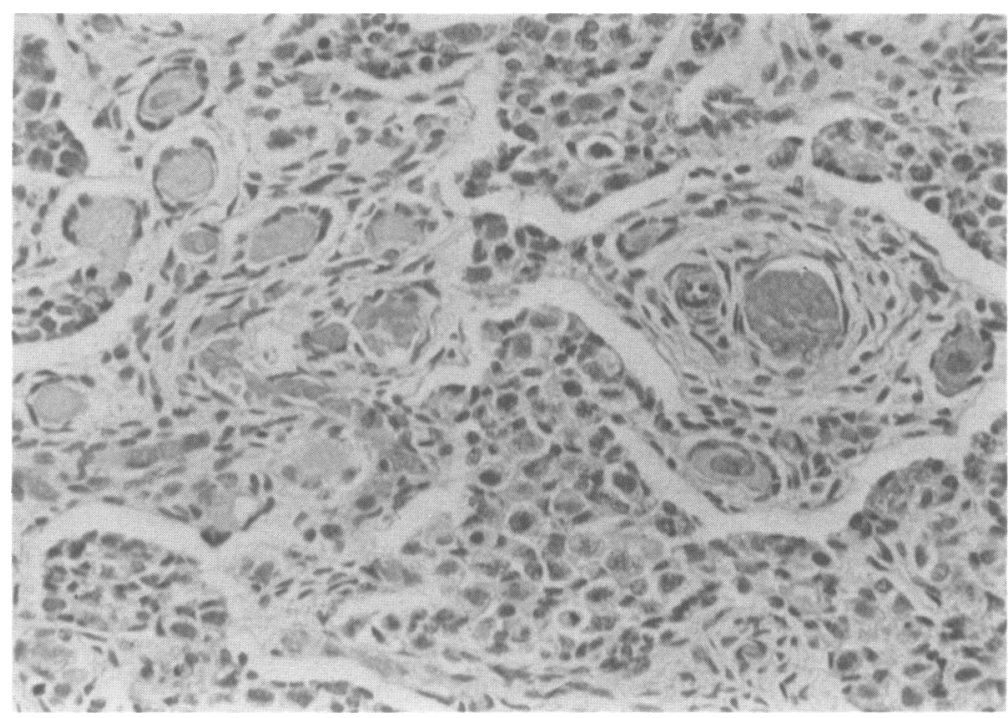

Ovary. Abnormal clumps of large basophilic cells lie in the spindle celled stroma surrounding normal ova. The cells stain positively with the monoclonal antibody CAM 5.2, an epithelial cell marker which also stains positively the surface layer of cells covering the ovary and the rim of cells round each ova.

chromosome, 46,X,del(X)(p11.2p11.4). Parental chromosomes were normal. From 29 weeks' gestation no oestriol could be detected in maternal urine.

At 31 weeks' gestation cortisol precursors and metabolites showed a marked deficit in a random maternal urine sample. Three months after delivery these levels fell within the normal range.

\section{Discussion}

These babies shared a number of common features, notably early lethality, postaxial polydactyly, $2 / 3$ syndactyly of the toes, short limbs, and small kidneys. Case $1 \mathrm{had}$ unilobular lungs and sex reversal, whereas case $\mathbf{2}$ had multiple internal anomalies involving the heart, lungs, pancreas, adrenals, and brain. These constellations of abnormalities closely resemble those described in other babies with SLO II, ${ }^{4}$ although we also record some new observations. The demonstration of reduced quantities of somatostatin in the pancreas of case $\mathbf{2}$ has not been specifically observed before. However, nesidioblastosis of the pancreas has been recorded in previous cases of this syndrome and, although in this case it would be hard to make the diagnosis confidently from the section examined, it is of interest that Bishop et $a l^{5}$ observed a correlation between decreased amounts of stainable somatostatin and nesidioblastosis. The implications of this association, however, are as yet unclear. The ovarian findings in case 2 are also unusual and may have been a consequence of the small $\mathrm{X}$ chromosome deletion, which is very unlikely to have contributed to the other much more serious abnormalities.

The combination of low maternal oestriol levels, sex reversal, and large adrenal glands suggests an underlying defect in fetal adrenal metabolism. The complete absence of lipid in the adrenal cortex of case 2 lends support to this hypothesis, as does the apparent suppression of maternal adrenal function in late pregnancy in both of these cases; this might have been secondary to fetomaternal transfer of high levels of an adrenal steroid which could not be processed normally by the fetal adrenals. We present these cases in the hope that colleagues who encounter similar cases will be encouraged to pursue investigation of both maternal and fetal adrenal status.

1 Curry CJR, Carey JC, Holland JS, et al. Smith-Lemli-Opitz syndrome-type II: multiple congenital anomalies with male pseudohermaphroditism and frequent early lethality. $\mathrm{Am} \mathrm{f} \mathrm{Med}$ Genet 1987;26:45-57.

2 Le Merrer M, Briard ML, Girard S, Mulliez N, Moraine C, Imbert MC. Lethal acrodysgenital dwarfism: a severe letha condition resembling Smith-Lemli-Opitz syndrome. $\mathcal{f}$ Med Genet 1988;25:88-95.

3 Donnai D, Young ID, Owen WG, Clark SA, Miller PFW, Knox WF. The lethal multiple congenital anomaly syndrome of polydactyly, sex reversal, renal hypoplasia, and unilobular lungs. 7 Med Genet 1986;23:64-71.

4 Donnai D, Burn J, Hughes H. Smith-Lemli-Opitz syndromes: do they include the Pallister-Hall syndrome? Am $\mathcal{J}$ Med Genet 1987;28:741-3.

5 Bishop AE, Polak JM, Gavin Chesa P, et al. Decrease of pancreatic somatostatin in neonatal nesidioblastosis. Diabetes 1981;30:122-6. 